\title{
Anesthesia Analepsia Management Improves Postoperative Stress Reaction and Oxygenation in Elderly Patients Undergoing Lumbar Spine Surgery
}

\section{Guifei Li ( $\sim$ GuifeiLi0411@yeah.net )}

Traditional Chinese Medicine Hospital of Shapingba District

\section{Zhi Chen}

Traditional Chinese Medicine Hospital of Shapingba District

Furong Tan

Traditional Chinese Medicine Hospital of Shapingba District

Qiang Huang

Traditional Chinese Medicine Hospital of Shapingba District

Yizhen Li

Traditional Chinese Medicine Hospital of Shapingba District

\section{Furong Su}

Traditional Chinese Medicine Hospital of Shapingba District

\section{Research Article}

Keywords: analepsia, anesthesia, lumbar spine surgery, stress reaction, oxygenation function

Posted Date: June 2nd, 2021

DOI: https://doi.org/10.21203/rs.3.rs-534726/v1

License: (c) (i) This work is licensed under a Creative Commons Attribution 4.0 International License. Read Full License 


\section{Abstract}

Background: Developing a scientific and effective anesthesia analepsia management strategy is of great significance to reduce the risk of complications in elderly patients. This study aims to explore the effect of analepsia management on the postoperative stress reaction and oxygenation in elderly patients with lumbar spine surgery.

Methods: In this randomized controlled study, 60 elderly patients who underwent lumbar spine surgery with general anesthesia in Traditional Chinese Medicine Hospital of Shapingba District, Chongqing City were included. According to the random number table method, patients were randomly divided into test group $(n=30)$ and control group $(n=30)$. During the analepsia period, patients in the control group received routine management, while the test group received a new analepsia management strategy based on the control group. The analepsia quality, postoperative stress reaction, oxygenation function, and complication rates of the two groups were compared.

Results: Compared with the control group, the extubation time, fully awake time, and resuscitation chamber residence time in test group were significantly shortened $(P<0.05)$. At different times postoperatively, the test group had significantly lower epinephrine, cortisol, and blood sugar levels than the control group $(P<0.001)$, and significantly higher or lower $\mathrm{PaO}_{2}$, oxygenation index $(\mathrm{OI})$, and $\mathrm{PaCO}_{2}$ values $(P<0.01)$. Compared with the control group, the postoperative visual analogue scale (VAS) score in the test group was lower ( $P \otimes 0.05)$, while the Quality of Recovery-40 (Q०R-40) score was higher (P凶0.05), and the test group had a lower incidence of restlessness, hypothermia and respiratory complications during the analepsia period $(P<0.05)$.

Conclusions: This study showed that the analepsia management strategy could improve the postoperative stress reaction and oxygenation function of elderly patients with lumbar spine surgery, which could promote the postoperative recovery of patients.

\section{Background}

The lumbar spine is a common site for orthopedic diseases, and the elderly is the largest subset of patients ${ }^{[1]}$. For most patients, surgery is still the main treatment method ${ }^{[2]}$.Compared with young patients, the physical and physiological functions of the elderly are significantly reduced, and the elderly often have multiple diseases, which significantly increases the risk of anesthesia ${ }^{[3]}$. In general anesthesia, the incidence of complications such as postoperative hypothermia, restlessness, hypoxemia, and cognitive dysfunction in the elderly is significantly higher than that in the young ${ }^{[3,4]}$. Anesthesiarelated complications, especially postoperative cognitive dysfunction, not only prolong the hospital stay and reduce the quality of life but also affect the prognosis of the disease and increase the risk of death ${ }^{[5-7]}$. Therefore, reducing the risk of anesthesia for elderly patients as much as possible is essential to improve the prognosis of patients. 
In the past few decades, clinical anesthesia methods for lumbar spine surgery were extensively and indepth studied, and many anesthetics and anesthesia programs were developed to further improve the effectiveness and safety of anesthesia ${ }^{[8,9]}$. However, there is currently no clinical anesthesia method that can completely avoid the risk of complications. It's worth emphasizing that the management during anesthesia is the main component of the patients' surgical process. Few clinical studies focused on further improving the quality of management during anesthesia, especially the analepsia period ${ }^{[10,11]}$. Therefore, developing a scientific and effective anesthesia analepsia management strategy is of great significance to reduce the risk of complications in elderly patients. In this study, we tailored an anesthesia analepsia management strategy for elderly patients undergoing lumbar spine surgery and focused on observing the effect of the strategy on the postoperative stress reaction and oxygenation function, in order to provide a clinical reference.

\section{Materials And Methods}

\subsection{Patients}

The study included 60 elderly patients who underwent lumbar spine surgery at Traditional Chinese Medicine Hospital of Shapingba District, Chongqing City from June 2019 to September 2020. Inclusion criteria: 1) Age $\geq 60$ years; 2) Classification of American Society of Anesthesiologists (ASA): 怄; 3 ) Volunteer to participate in this study and receive elective general anesthesia for lower lumbar spine surgery. Exclusion criteria: 1) Patients previously received lumbar spine surgery; 2) Patients with severe complications such as severe heart, lung, kidney, and liver dysfunction; 3) Patients with severe cognitive dysfunction and other mental illnesses; 4) Patients with diabetes; 5) Patients toke the sedatives or antidepressants for a long time before surgery; 6) Patients with severe vision and/or hearing impairment. The patients were randomly divided into the test group $(n=30)$ and the control group $(n=30)$ using the random number table method.

\subsection{Ethical statement}

This study followed the purpose of the Declaration of Helsinki and was approved by the ethics committee of Traditional Chinese Medicine Hospital of Shapingba District, Chongqing City (No. SPBZYY201901ES). All the patients were informed of the contents of this study and signed an informed consent form.

\subsection{Anesthesia analepsia management}

The patients in the control group were given routine management in the operating room: Preoperative visits were performed on the patients; Baseline information such as the patient's name and age were checked in detail; The precautions during the operation were explained. After the operation, the patients' symptoms and signs were closely monitored. The temperature of the operating room environment was adjusted to be appropriate; The patients' body temperatures are monitored; Liquids such as infusion and irrigation fluids were heated. 
Patients in the test group were treated with anesthesia analepsia management strategy on the basis of the control group, including the comprehensive management, which was from preoperative to postoperative extubation process ${ }^{[12,13]}$. The anesthesia analepsia management strategy is shown in Table 1.

\subsection{Outcome measures}

\section{Main outcome measures:}

1) Analepsia quality: including spontaneous breathing recovery time, extubation time, fully awake time, and resuscitation chamber residence time.

2) Stress reaction: When the patient enters the PACU, $3 \mathrm{ml}$ of peripheral venous blood is drawn at $12 \mathrm{~h}$ and 48h after the operation, epinephrine, cortisol, and the blood glucose, levels of the patient in the fasting state are detected by an automatic biochemical analyzer.

3) Oxygenation function: When the patient enters the PACU, at $12 \mathrm{~h}$ and $24 \mathrm{~h}$ after the operation, the patient's arterial blood is taken for blood gas analysis, and the arterial partial pressure of oxygen $\left(\mathrm{PaO}_{2}\right)$, the arterial partial pressure of carbon dioxide $\left(\mathrm{PaCO}_{2}\right)$ and oxygenation index $(\mathrm{OI})$.

\section{Secondary outcome measures:}

1) Postoperative pain and early recovery quality: The pain level of patients at $2 \mathrm{~h}, 4 \mathrm{~h}, 12 \mathrm{~h}, 24 \mathrm{~h}$, and $48 \mathrm{~h}$ after surgery was evaluated by the Visual Analogue Scale (VAS) ${ }^{[14]}$, with a total score of $0-10$. The higher the score, the more severe the patient's pain. The quality of early recovery of patients at $12 \mathrm{~h}, 24 \mathrm{~h}$, and $48 \mathrm{~h}$ after surgery was evaluated by the surgical 40-item recovery quality score (QoR-40) ${ }^{[15]}$, and the preoperative $1 \mathrm{~d}$ was used as a reference. The scale is out of 200 points. The higher the score, the better the patient's recovery quality.

2) Complication rates: Record the incidence of restlessness, hypothermia, and respiratory system complications (hypoxemia, glossoptosis, laryngeal edema, etc.) during the analepsia period.

\subsection{Statistical analysis}

SPSS version 23.0 (SPSS, Inc., Chicago, IL, USA) software was applied for statistical analysis of the data. Enumeration data were expressed as the number of cases (percentage) [n (\%)], a chi-square test was performed in parallel, and $a=0.05$ was selected as test level; measurement data in the study conformed to a normal distribution, expressed as mean \pm standard deviation( $\pm s)$, independent sample t-test was used for comparison, paired t-test was used for comparison before and after the same group, and $a=$ 0.05 was selected as test level; $P<0.05$ indicated a statistically significant difference.

\section{Results}




\subsection{Baseline}

There was no significant difference in gender, age, BMI value, type of lumbar spine disease, and ASA classification between the two groups (all $P>0.05$ ) (Table 2).

\subsection{Analepsia quality}

The two groups of patients had similar spontaneous breathing recovery time (Table 3), and there was no significant difference ( $P>0.05)$. However, compared with the control group, the extubation time, fully awake time, and resuscitation chamber residence time were significantly shortened in the experimental group (all $P<0.001$ ) (Table 3 ).

\subsection{Postoperative stress reaction}

The postoperative epinephrine, cortisol, and blood glucose levels of the patients showed a gradual decrease (Figure 1). There was no significant difference in epinephrine, cortisol and blood glucose levels between the two groups of patients when they entered PACU ( $P>0.05)$. Compared with the control group, the test group had significantly lower levels of epinephrine (Figure 1A), cortisol (Figure 1B) and blood sugar (Figure $1 \mathrm{C})$ at $12 \mathrm{~h}$ and $48 \mathrm{~h}$ after surgery, with significant differences $(P<0.05)$.

\subsection{Postoperative oxygenation function}

$\mathrm{PaO}_{2}$ and $\mathrm{OI}$ of the two groups of patients decreased firstly and increased after the operation then. In contrast, $\mathrm{PaCO}_{2}$ increased firstly and decreased then (Figure 2). There was no significant difference between the two groups of patients in $\mathrm{PaO}_{2}, \mathrm{PaCO}_{2}$ and OI when they entered PACU ( $\left.P>0.05\right)$. Compared with the control group, the test group had significantly higher $\mathrm{PaO}_{2}$ and $\mathrm{Ol}$ values at $12 \mathrm{~h}$ and $24 \mathrm{~h}$ postoperatively (Figure 2A, 2C), while PaCO2 was significantly lower (Figure 2B), and there were significant differences between the groups $(P<0.01)$.

\subsection{Postoperative VAS and QoR-40 score}

The VAS scores of the two groups showed a trend of increasing firstly and decreasing then (Figure $3 \mathrm{~A}$ ), while the QoR-40 score decreased firstly and increased then (Figure 3B). There was no significant difference in VAS scores between the two groups at $2 \mathrm{~h}$ postoperatively $(P>0.05)$, while the VAS scores of the experimental group were significantly lower than those of the control group at $4 \mathrm{~h}, 12 \mathrm{~h}$, and $24 \mathrm{~h}$ postoperatively $(P<0.01)$ (Figure $3 \mathrm{~A})$. There was no significant difference in the VAS score of the two groups at 48 hours postoperatively $(P>0.05)$. The preoperative QoR-40 scores of the two groups were not significantly different ( $P>0.05)$. Compared with the control group, the test group had significantly higher QoR-40 scores at 12h, 24h, and 48h postoperatively ( $P<0.01)$ (Figure 3B).

\subsection{Complication rates}


Compared with the control group, the incidence of restlessness in the analepsia period, hypothermia and respiratory complications in the test group were significantly reduced $(P<0.05)$ (Table 4$)$.

\section{Discussion}

Continued advancement of anesthesia technology and the emergence of more effective and safer anesthetics have improved the safety of elderly patients during the perioperative period. However, due to the obvious decline in the functions of the various organs of the elderly and a variety of comorbidities, completely eliminating the risks of anesthesia and surgery is still a huge clinical challenge. In particular, complications during the analepsia period, such as delirium, restlessness during recovery, tachycardia, elevated blood pressure, hypoxemia, and varying degrees of consciousness disturbance, have seriously affected the safety of patients during the perioperative period and the prognosis of the operation ${ }^{[3,4]}$. In this study, we tailored a systematic analepsia management strategy based on the clinical characteristics of elderly patients undergoing lumbar spine surgery, in order to improve the analepsia quality and reduce the risk of anesthesia complications. The results of the study showed that the new analepsia management strategy effectively improved the analepsia quality for elderly patients undergoing lumbar spine surgery, and postoperative stress reaction and oxygenation function got improved as well.

Surgical trauma, anesthesia operations, and emotional changes during the perioperative period all cause a strong stress reaction in patients ${ }^{[16]}$. In the process of tracheal intubation and tracheal extubation, the strong stimulation of the tracheal tube to the sidewall and glottis of the trachea can reflexly excite the sympathetic nerves, resulting in increased secretion of catecholamines in the body, the blood pressure and heart rate got increased, which seriously affects the patients' health life safety ${ }^{[17,18]}$. The stress reaction also promotes the catabolism of sugar, protein and fat, causing continuous increase in blood sugar during and after surgery, leading to difficulty in wound healing and prone to infection ${ }^{[19,20]}$. The results of this study showed that the adrenaline, cortisol, and blood sugar levels of the test group at $12 \mathrm{~h}$ and $48 \mathrm{~h}$ after surgery were significantly lower than those of the control group, indicating that systematic analepsia management strategy can effectively reduce the patients' stress reaction. We analyzed that comprehensive evaluation and active psychological intervention before surgery effectively improved the patients' mental state and reduced the stress reaction caused by mood swings. Previous studies confirmed that interventions in patients with negative emotions could effectively reduce postoperative stress reaction and complication rates ${ }^{[21,22]}$. In addition, by screening high-risk patients for special attention, targeted intervention could be carried out during surgery period and the analepsia period after surgery, especially the comprehensive management of PACU, which could effectively reduce anesthesiarelated complications and thereby reduce the stress reaction.

Many anesthetics can affect the oxygenation function of patients, especially opioids, which can produce obvious respiratory depression ${ }^{[23]}$. The lung reserve capacity of the elderly is significantly lower than that of the young, and elderly patients are prone to decreased oxygenation in the lungs, impaired lung function, and increased pulmonary complications after general anesthesia. In addition, since the basal 
metabolism of the elderly is significantly reduced, residual muscle relaxants are more likely to occur. Studies have confirmed that the residual muscle relaxants significantly increased the respiratory system complications such as airway obstruction, hypoxemia, and respiratory failure ${ }^{[24]}$. In the management of analepsia period, we emphasized the monitoring of the oxygenation function of the patient, and the dynamic monitoring of postoperative drug residues, poor breathing, and upper respiratory tract obstruction, so as to effectively prevent complications such as hypoxemia. Study showed that $1 / 3$ of the complications in the recovery period were respiratory and airway complications, and these complications were closely related to tracheal extubation ${ }^{[25]}$. We compared the oxygenation function of the two groups of patients at $12 \mathrm{~h}$ and $24 \mathrm{~h}$ after surgery. The results showed that the test group had significantly higher $\mathrm{PaO}_{2}$, Ol and lower $\mathrm{PaCO}_{2}$ values than the control group, which suggests that anesthesia recovery management can effectively improve patients' oxygenation function after the surgical procedures. We analyzed that this may be related to the scientific extubation procedure in the management of analepsia period, and we emphasized the appropriate extubation time and extubation method. Extubation in $60^{\circ}$ not only reduced the force of extubation, but also reduced the impact on the patients' hemodynamics ${ }^{[13]}$. Keeping a moderate airbag and tracheal pressure during extubation can effectively remove secretions above the airbag, reduce side effects during extubation, and prevent respiratory complications.

Continuous and rigorous monitoring after extubation and intervention after analepsia further ensured the free of residual muscle relaxants and related complications ${ }^{[26]}$.

The VAS scores of the two groups of patients at different times after surgery showed that the postoperative pain of the test group was significantly reduced, and the VAS scores were lower than the control group at $4 \mathrm{~h}, 12 \mathrm{~h}$, and $24 \mathrm{~h}$ after surgery. The test group had higher QoR-40 scores at $12 \mathrm{~h}, 24 \mathrm{~h}$, and $48 \mathrm{~h}$ after surgery, indicating that the test group had better postoperative recovery quality than the control group. We analyzed that it may be related to the significant reduction of the stress reaction and the lower incidence of complications.

The limitation of this study is that the sample size is small, and the disease type of elderly patients admitted is small. Thus, we need to further increase the sample size and verify the effectiveness of analepsia management strategy in elderly patients with other diseases. Besides, we lack a longer followup of the elderly patients after surgery, and the effect of anesthesia recovery management on the longterm outcome of patients is still unclear. We plan to remedy these limitations in future research.

Overall, the results of this study showed that the analepsia management strategy could improve the postoperative stress reaction and oxygenation function, reduce the risk of perioperative complications, and promote rapid postoperative recovery of elderly patients undergoing lumbar spine surgery.

\section{Abbreviations}

$\mathrm{PaO}_{2}$ : Pressure of oxygen; $\mathrm{PaCO}_{2}$ : Pressure of carbon dioxide; Ol: Oxygenation index; QoR-40: the surgical 40-item recovery quality score; PACU: Post Anesthesia Care Unit; BMI: Body Mass Index; ASA: American Society of Anesthesiologists; VAS: Visual Analogue Scale. 


\section{Declarations}

Acknowledgements

Not applicable.

\section{Authors' contributions}

GF, ZC and FR(Tan) participated in project design, clinical data collection, data statistical analysis and collation, and article writing. Q, YZ, and FR(Su) participated in clinical data collection. All authors have read and approved the manuscript.

\section{Ethics approval and consent to participate}

This study followed the purpose of the Declaration of Helsinki and was approved by the ethics committee of Traditional Chinese Medicine Hospital of Shapingba District, Chongqing City (No. SPBZYY201901ES). All the patients were informed of the contents of this study and signed an informed consent form.

\section{Funding}

No funding was received for this study.

\section{Availability of data and materials}

The datasets used and/or analysed during the current study are available from the corresponding author on reasonable request.

\section{Consent for publication}

Not applicable.

\section{Competing interests}

No conflict of interests existed in this study.

\section{Author details}

1. Department of Anesthesiology, Traditional Chinese Medicine Hospital of Shapingba District, Chongqing City, Shapingba District, Chongqing 400030, P.R.China.

2. Department of Orthopedics, Traditional Chinese Medicine Hospital of Shapingba District, Chongqing City, Shapingba District, Chongqing 400030, P.R.China.

\section{References}


1. Goubert D, De Pauw R, Meeus $M$, et al. Lumbar muscle structure and function in chronic versus recurrent low back pain: a cross-sectional study[J]. Spine J, 2017, 17(9): 1285-1296.

2. Abbatematteo JM, Uribe JS. Commentary: Prognostic Factors for Adjacent Segment Disease After L4-L5 Lumbar Fusion[J]. Neurosurgery, 2020, 86(6): E528.

3. Strøm C, Rasmussen LS, Sieber FE. Should general anaesthesia be avoided in the elderly?[J]. Anaesthesia, 2014, 69 Suppl 1(Suppl 1): 35-44.

4. Evered L, Scott DA, Silbert B. Cognitive decline associated with anesthesia and surgery in the elderly: does this contribute to dementia prevalence?[J]. Curr Opin Psychiatry, 2017, 30(3): 220-226.

5. Tzimas P, Samara E, Petrou A, et al. The influence of anesthetic techniques on postoperative cognitive function in elderly patients undergoing hip fracture surgery: General vs spinal anesthesia[J]. Injury, 2018, 49(12): 2221-2226.

6. Shaw CA, Steelman VM, Deberg J, et al. Effectiveness of active and passive warming for the prevention of inadvertent hypothermia in patients receiving neuraxial anesthesia: A systematic review and meta-analysis of randomized controlled trials[J]. J Clin Anesth, 2017, 38(93-104.

7. Patel V, Champaneria R, Dretzke J, et al. Effect of regional versus general anaesthesia on postoperative delirium in elderly patients undergoing surgery for hip fracture: a systematic review[J]. BMJ Open, 2018, 8(12): e020757.

8. Raja SD, Shetty AP, Subramanian B, et al. A prospective randomized study to analyze the efficacy of balanced pre-emptive analgesia in spine surgery[J]. Spine J, 2019, 19(4): 569-577.

9. Deng H, Coumans JV, Anderson R, et al. Spinal anesthesia for lumbar spine surgery correlates with fewer total medications and less frequent use of vasoactive agents: A single center experience[J]. PLoS One, 2019, 14(6): e0217939.

10. Mills GH. Respiratory complications of anaesthesia[J]. Anaesthesia, 2018, 73 Suppl 1(25-33.

11. Davidson AJ, Morton NS, Arnup SJ, et al. Apnea after Awake Regional and General Anesthesia in Infants: The General Anesthesia Compared to Spinal Anesthesia Study-Comparing Apnea and Neurodevelopmental Outcomes, a Randomized Controlled Trial[J]. Anesthesiology, 2015, 123(1): 3854.

12. Artime CA, Hagberg CA. Tracheal extubation[J]. Respir Care, 2014, 59(6): 991-1002; discussion 1002-1005.

13. Kido H, Komasawa N, Imajo Y, et al. Evaluation of double-lumen endotracheal tube extubation force by extraction angle: a prospective randomized clinical trial[J]. J Clin Anesth, 2016, 29(40-45.

14. Voutilainen A, Pitkäaho T, Kvist T, et al. How to ask about patient satisfaction? The visual analogue scale is less vulnerable to confounding factors and ceiling effect than a symmetric Likert scale[J]. J Adv Nurs, 2016, 72(4): 946-957.

15. Myles PS. Measuring quality of recovery in perioperative clinical trials[J]. Curr Opin Anaesthesiol, 2018, 31(4): 396-401. 
16. Li Y, Dong H, Tan S, et al. Effects of thoracic epidural anesthesia/analgesia on the stress response, pain relief, hospital stay, and treatment costs of patients with esophageal carcinoma undergoing thoracic surgery: A single-center, randomized controlled trial[J]. Medicine (Baltimore), 2019, 98(7): e14362.

17. Davis J, Sreevastava DK, Dwivedi D, et al. A Comparison of Stress Response between Insertion of Gastro-laryngeal Tube and Endotracheal Intubation in Patients Undergoing Upper Gastrointestinal Endoscopic Procedures for Endoscopic Retrograde Cholangiopancreatography[J]. Anesth Essays Res, 2019, 13(1): 13-18.

18. Wang $\mathrm{CH}$, Luo J, Li J, et al. Efficacy of inhalational sevoflurane anesthesia induction on inhibiting the stress response to endotracheal intubation in children with congenital heart disease[J]. Eur Rev Med Pharmacol Sci, 2018, 22(4): 1113-1117.

19. Goiato MC, Da Silva EVF, Cândido NB, et al. Evaluation of the level of cortisol, capillary blood glucose, and blood pressure in response to anxiety of patients rehabilitated with complete dentures[J]. BMC Oral Health, 2019, 19(1): 75.

20. Marik PE, Bellomo R. Stress hyperglycemia: an essential survival response![J]. Crit Care, 2013, 17(2): 305.

21. Cattaneo A, Riva MA. Stress-induced mechanisms in mental illness: A role for glucocorticoid signalling[J]. J Steroid Biochem Mol Biol, 2016, 160(169-174.

22. Broadbent $E$, Kahokehr $A$, Booth $R J$, et al. A brief relaxation intervention reduces stress and improves surgical wound healing response: a randomised trial[J]. Brain Behav Immun, 2012, 26(2): 212-217.

23. Boom M, Niesters $M$, Sarton $E$, et al. Non-analgesic effects of opioids: opioid-induced respiratory depression[J]. Curr Pharm Des, 2012, 18(37): 5994-6004.

24. Norton $M$, Xará D, Parente $D$, et al. Residual neuromuscular block as a risk factor for critical respiratory events in the post anesthesia care unit[J]. Rev Esp Anestesiol Reanim, 2013, 60(4): 190196.

25. Jain N, Mathur PR, Khan S, et al. Effect of bispectral index versus end-tidal anesthetic gas concentration-guided protocol on time to tracheal extubation for halothane-based general anesthesia[J]. Anesth Essays Res, 2016, 10(3): 591-596.

26. Labaste F, Silva S, Serin-Moulin L, et al. Predictors of desaturation during patient transport to the postoperative anesthesia care unit: an observational study[J]. J Clin Anesth, 2016, 35(210-214.

\section{Tables}


Items Specific content

Comprehensive preoperative evaluation

High-risk population screening

Mental State Assessment

Preoperative psychological management
According to the patients' age, weight, medical history, surgery method, anesthesia plan, etc., patients with high risks of restlessness and respiratory complications during the analepsia period were screened out, and focused attention, and closely monitored.

Effectively communication with the patients was processed before the operation. The patients' cognitive and psychological status were assessed. According to the patients' education level, occupation, family and other conditions, preventive and targeted management was given.

The anxiety and tension of the patients were relieved to alleviate the psychological stress. After entering the operating room, we communicated with the patient and diverted their attention.

Intraoperative

risk

management

Body

temperature management

Infusion management

Respiratory management

Analepsia management in the PACU

Normal management

\section{Body}

temperature monitoring

Oxygenation function monitoring

Pain intervention
Warming blankets are used to maintain the patient's normal body temperature. For patients with hypothermia, hang a red low temperature sign on the bedside and cover with a quilt, and pay attention to hyperthermia.

Precisely calculate the input and output volume during the operation, strictly control the input and output liquid volume, and adjust the drip rate.

Maintain unobstructed breathing and clear respiratory secretions in time.
After entering PACU, check the information carefully and adopt a proper posture. Monitor the patient's blood pressure, heart rate, blood gas and other indicators dynamically to adjust the signs of imbalance. Observe the state of consciousness dynamically and adjust the oxygen flow rate to avoid aspiration.

Monitor changes in body temperature and control the temperature at $25^{\circ} \mathrm{C}$ to avoid overheating caused by overheating.

Strengthen arterial blood gas analysis, and dynamically monitor postoperative drug residues, poor breathing, and upper respiratory tract obstruction to prevent hypercapnia and hypoxemia.

Play soft, soothing, calm music, maintain the volume at $25 \mathrm{~dB}$, and continue to play in a loop until the patient wakes up. According to the patient's postoperative pain, use analgesics as prescribed by the doctor.

PACU: post-anesthesia care unit. 
Items

Master the timing of extubation

\section{Specific content}

When the patient's breathing rate is $<30$ breaths/min, the peak inspiratory pressure is $<-20 \mathrm{cmH} 2 \mathrm{O}(1 \mathrm{cmH} 2 \mathrm{O}=0.098 \mathrm{kPa})$, the vital capacity is $>15 \mathrm{ml} / \mathrm{kg}$, the tidal volume is $>6 \mathrm{ml} / \mathrm{kg}$, the hemodynamics is stable, no additional support is needed, and the gas exchange is sufficient. ( $\mathrm{SpO} 2 \geq 93 \%$, measuring arterial blood gas without acidosis when possible) and good recovery of muscle relaxation (head up for more than 5 seconds), extubation may be considered.

Master the extubation technique

Intervention after awakening
Extubation in $60^{\circ}$. Keep moderate airbag and tracheal pressure during extubation.

Prepare first aid supplies. Pay close attention to whether there are residual muscle relaxants. If the patient has abdominal breathing, shortness of breath, weakness, painful expression, etc., report to the doctor in time, open the airway, give oxygen with a mask, and use the antagonist in time. Instruct the patient to relax and breathe evenly.

PACU: post-anesthesia care unit.

Table 2

Baseline data

\begin{tabular}{|c|c|c|c|c|}
\hline Items & Test group $(n=30)$ & Control group $(n=30)$ & $t / \chi^{2}$ & $\mathbf{P}$ \\
\hline \multicolumn{5}{|l|}{ Gender $[\mathrm{n}(\%)]$} \\
\hline Male & $12(40.00)$ & $15(50.00)$ & \multirow[t]{2}{*}{0.606} & \multirow[t]{2}{*}{0.436} \\
\hline Female & $18(60.00)$ & $15(50.00)$ & & \\
\hline Age (year) & $68.2 \pm 5.5$ & $67.8 \pm 6.2$ & 0.264 & 0.793 \\
\hline BMI $\left(\mathrm{kg} / \mathrm{m}^{2}\right)$ & $23.2 \pm 2.5$ & $22.8 \pm 2.4$ & 0.632 & 0.530 \\
\hline \multicolumn{5}{|c|}{ Types of lumbar disease [n(\%)] } \\
\hline Spinal stenosis & $8(26.67)$ & $11(36.67)$ & \multirow[t]{2}{*}{0.693} & \multirow[t]{2}{*}{0.405} \\
\hline Lumbar disc herniation & $22(73.33)$ & $19(63.33)$ & & \\
\hline \multicolumn{5}{|l|}{ ASA classification [n(\%)] } \\
\hline grade $\otimes$ & $21(70.00)$ & $23(76.67)$ & \multirow[t]{2}{*}{0.341} & \multirow[t]{2}{*}{0.559} \\
\hline grade $\otimes$ & $9(32.50)$ & $7(23.33)$ & & \\
\hline
\end{tabular}


Table 3

Evaluation of analepsia quality

\begin{tabular}{|lllll|}
\hline Items & $\begin{array}{l}\text { Test group }(\mathrm{n}= \\
\mathbf{3 0})\end{array}$ & $\begin{array}{l}\text { Control group }(\mathrm{n}= \\
\mathbf{3 0})\end{array}$ & $\mathbf{t}$ & $\mathbf{P}$ \\
\hline $\begin{array}{l}\text { Spontaneous breathing recovery time } \\
\text { (min) }\end{array}$ & $14.9 \pm 2.3$ & $14.8 \pm 2.5$ & 0.161 & 0.873 \\
\hline Extubation time (min) & $16.2 \pm 2.5$ & $19.5 \pm 3.2$ & 4.451 & $<$ \\
\hline Fully awake time (min) & $21.8 \pm 3.1$ & $29.5 \pm 4.5$ & 7.718 & $<$ \\
\hline $\begin{array}{l}\text { Resuscitation chamber residence time } \\
\text { (min) }\end{array}$ & $30.3 \pm 3.4$ & $45.8 \pm 4.2$ & 15.711 & $<$ \\
\hline
\end{tabular}

Table 4

Complication rates in the patients.

\begin{tabular}{|c|c|c|c|c|}
\hline Complications & $\begin{array}{l}\text { Test group }(n= \\
30)\end{array}$ & $\begin{array}{l}\text { Control group }(n= \\
30)\end{array}$ & $\chi^{2} / t$ & $\mathbf{P}$ \\
\hline $\begin{array}{l}\text { Restlessness in the analepsia period } \\
{[\mathrm{n}(\%)]}\end{array}$ & $2(6.67)$ & $8(26.67)$ & 4.320 & 0.038 \\
\hline Hypothermia [n(\%)] & $1(3.33)$ & $6(20.00)$ & 4.043 & 0.044 \\
\hline \multicolumn{5}{|l|}{$\begin{array}{l}\text { Respiratory system complications } \\
\text { [n(\%)] }\end{array}$} \\
\hline Hypoxemia & $1(3.33)$ & $3(7.50)$ & & \\
\hline Glossoptosis & $0(0.00)$ & $3(10.00)$ & & \\
\hline Laryngeal edema & $0(0.00)$ & $2(6.67)$ & & \\
\hline Total & 1 (3.33) & 8 (26.67) & 6.405 & 0.011 \\
\hline
\end{tabular}

\section{Figures}


A

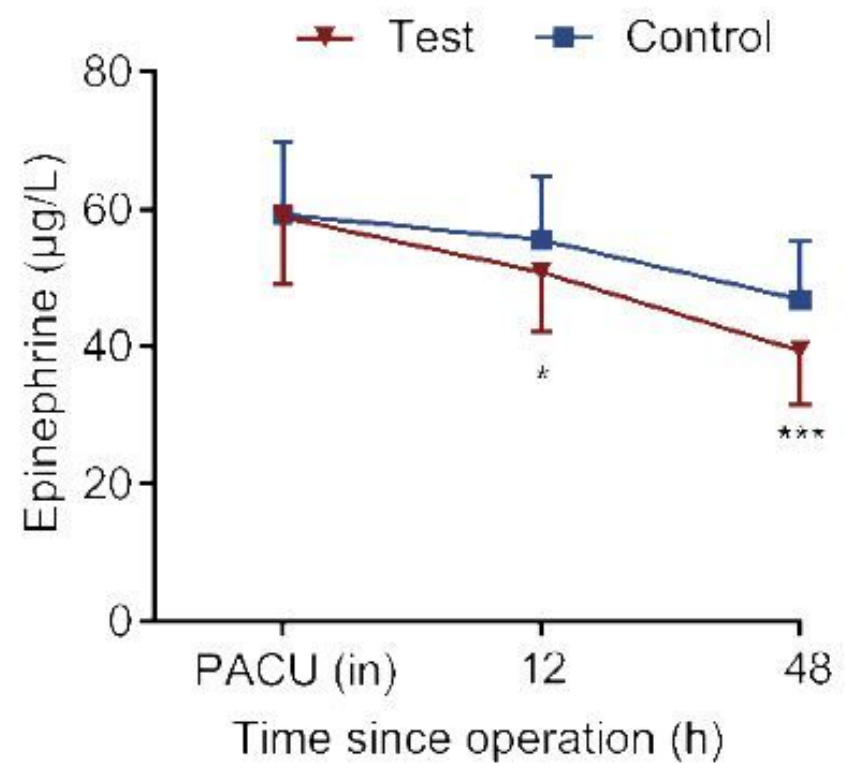

B

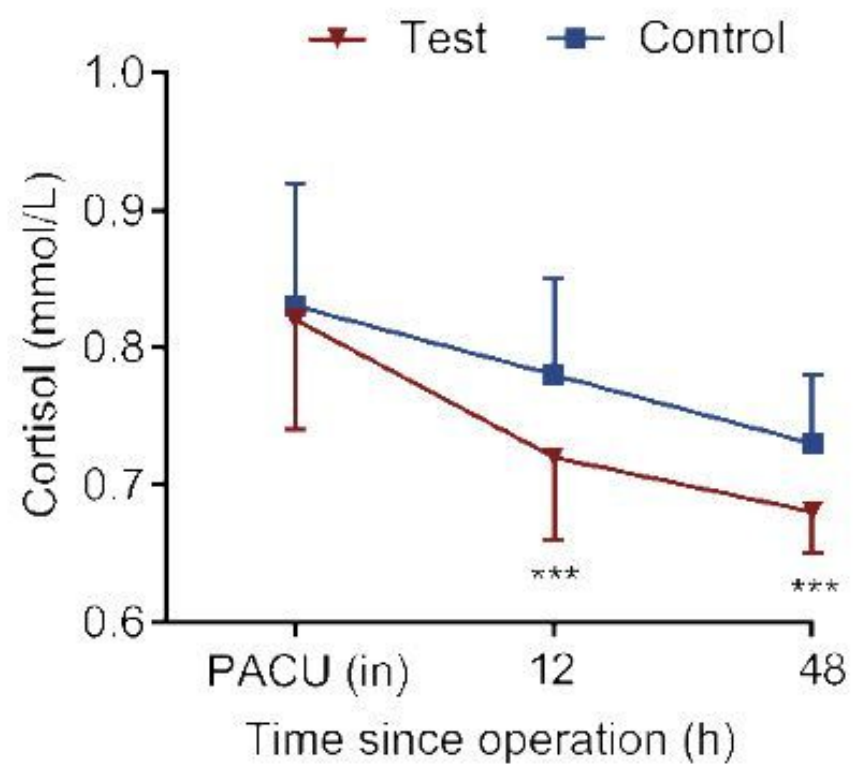

C

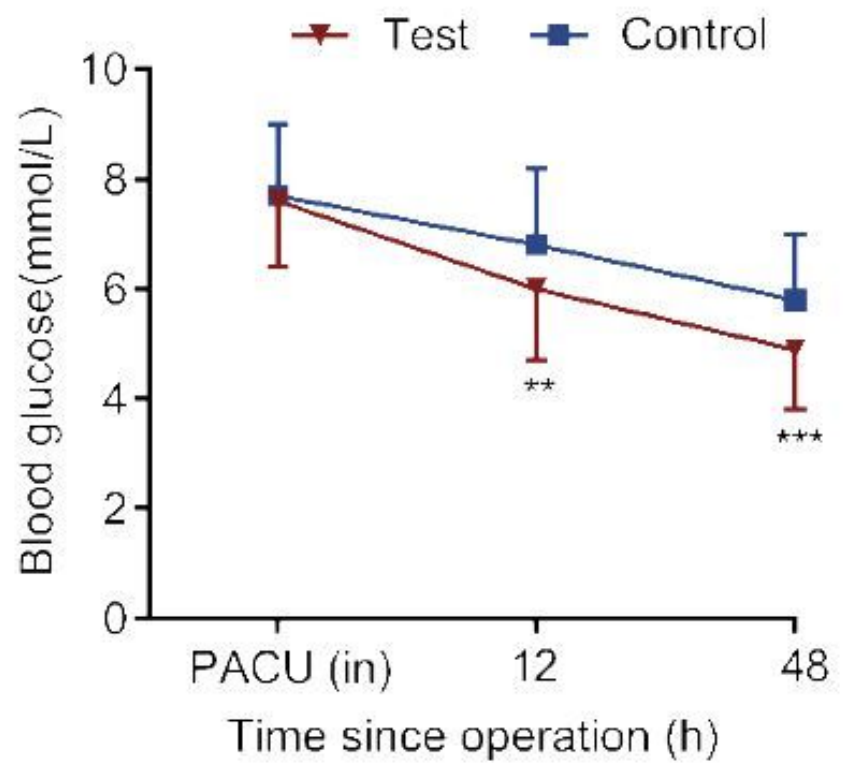

Figure 1

Changes in postoperative stress reaction. A. Epinephrine; B. Cortisol; C. Blood glucose. Compared with the control group, ${ }^{*}<<0.05,{ }^{\star} \mathrm{P}<0.01,{ }^{\star} * \star P<0.001$. $P A C U$ means post anesthesia care unit. 
A

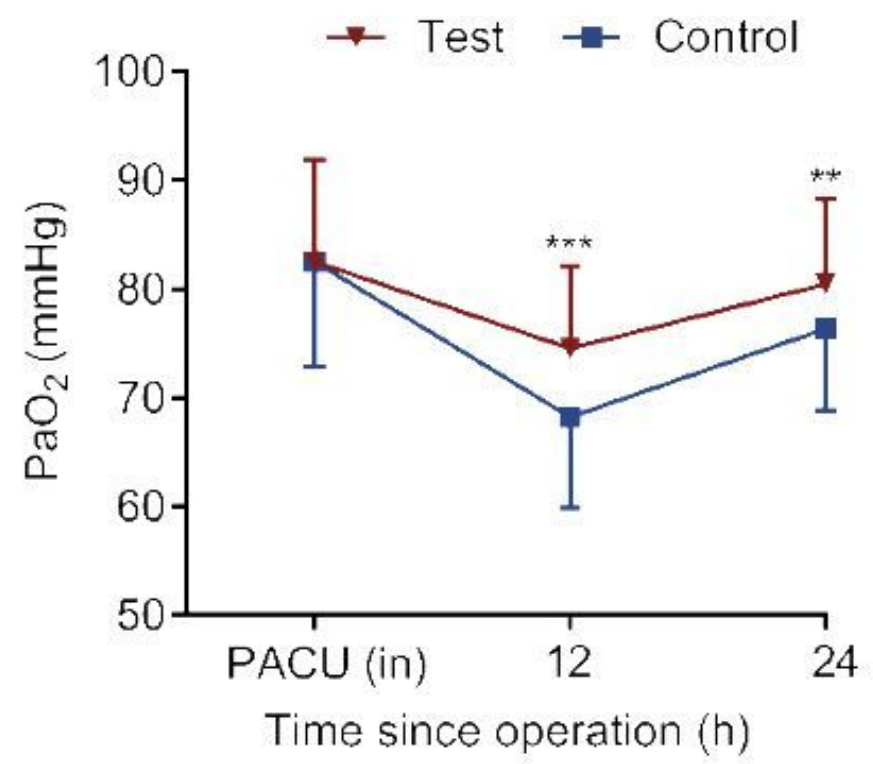

B

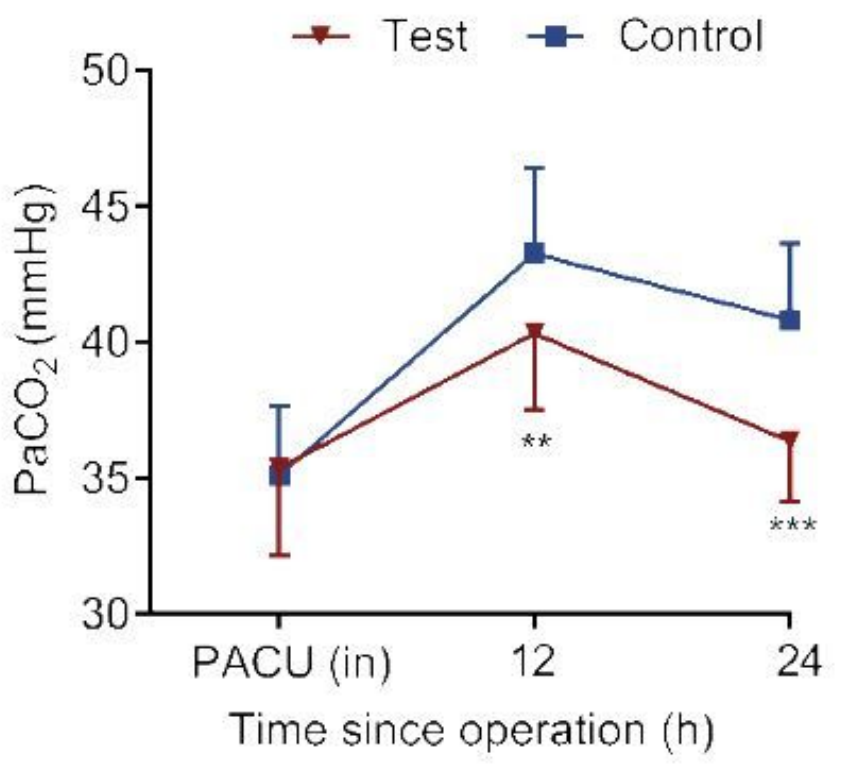

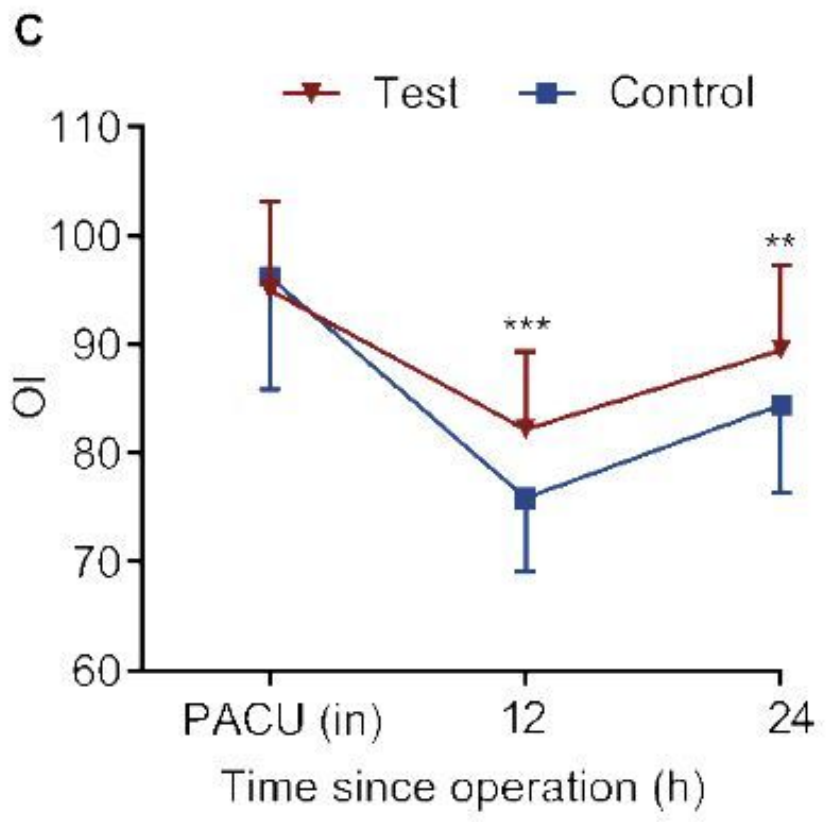

Figure 2

Changes in postoperative oxygenation function. A. PaO2; B. PaCO2; C. Ol. Compared with the control group, ${ }^{\star *} \mathrm{P}<0.01,{ }^{\star \star *} \mathrm{P}<0.001$. $\mathrm{PaO} 2$ means arterial partial pressure of oxygen $\square \mathrm{PaCO} 2$ means arterial blood partial pressure of carbon dioxide. OI means Oxygenation index. PACU means post anesthesia care unit. 
A

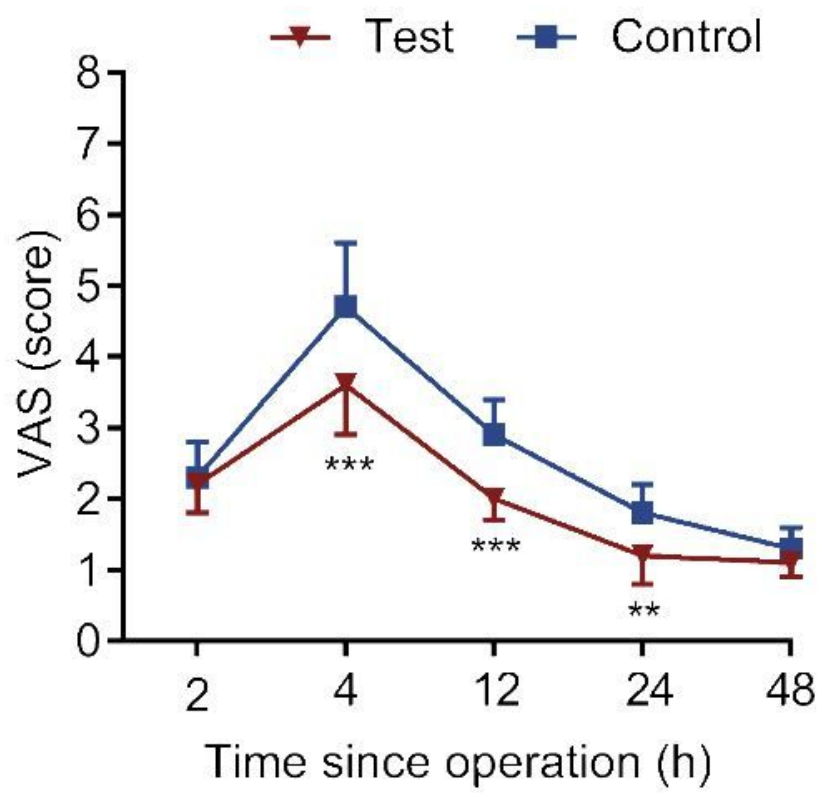

B

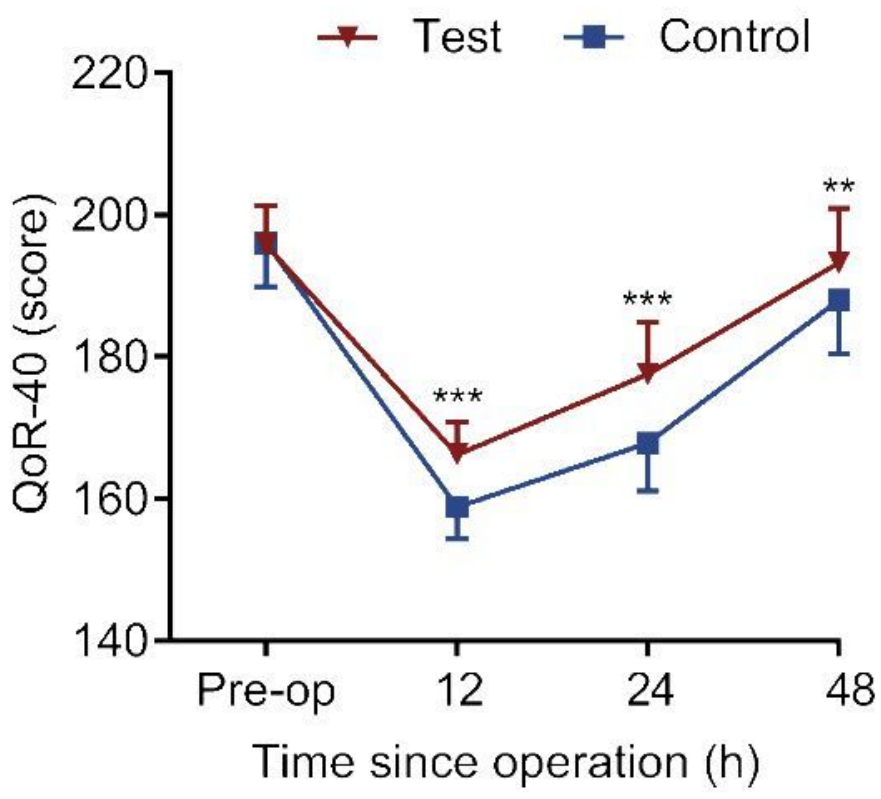

\section{Figure 3}

Changes in postoperative VAS and QoR-40 Scores. A. VAS score. B. QoR-40 score. VAS means visual analogue scale. QoR-40 means the Quality of Recovery-40 scale. 